\title{
First-Principles Molecular Dynamics Study of
}

\section{Silicon-based Ceramics: Different Tribochemical}

\section{Reaction Mechanisms during the Running-in Period}

\section{of Silicon Nitride and Silicon Carbide}

Yusuke Ootani, ${ }^{\dagger}$ Jingxiang Xu, ${ }^{\ddagger}$ Koshi Adachi,${ }^{\S}$ and Momoji Kubo ${ }^{\dagger *}$

†Institute for Materials Research, Tohoku University, 2-1-1 Katahira, Aoba-ku, Sendai, 980-8577,

Japan, ${ }^{\star}$ College of Engineering Science and Technology, Shanghai Ocean University, Shanghai,

201306, China, and ${ }^{\S}$ Department of Mechanical Systems Engineering, Graduate School of

Engineering, Tohoku University, 6-6-01 Aoba, Aramaki, Aoba-ku, Sendai, 980-8579, Japan. 
(a)

$\mathrm{OH}$ - and $\mathrm{H}$-termination

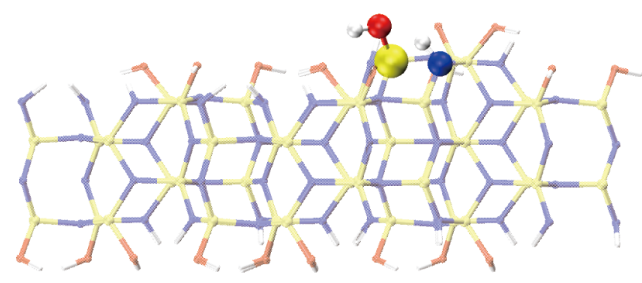

$0.0 \mathrm{~kJ} / \mathrm{mol}$

(b)

\section{$\mathrm{OH}$ - and $\mathrm{H}$-termination}

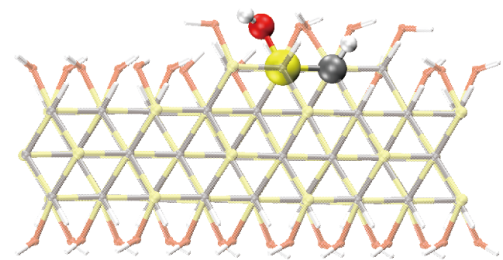

$0.0 \mathrm{~kJ} / \mathrm{mol}$
One $\mathrm{OH}$ - and $\mathrm{H}$-termination are swapped

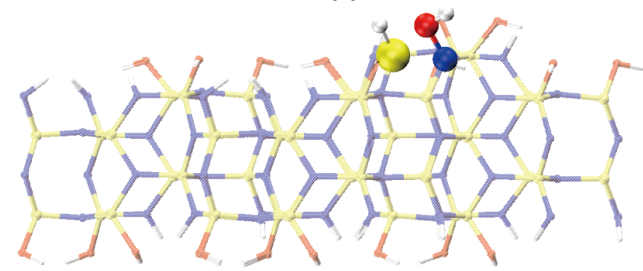

$370.0 \mathrm{~kJ} / \mathrm{mol}$

One $\mathrm{OH}$ - and $\mathrm{H}$-termination are swapped

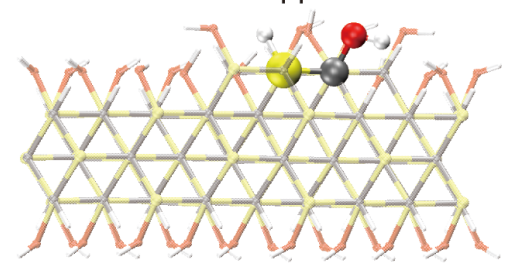

$243.0 \mathrm{~kJ} / \mathrm{mol}$

Figure S1. Optimized structure of the (a) $\mathrm{S}_{\mathrm{i} 3} \mathrm{~N}_{4}$ and (b) $\mathrm{SiC}$ slabs with an asperity. In the slabs on the left-hand side, all $\mathrm{Si}$ atoms on the surfaces are terminated by $\mathrm{OH}$ groups, whereas all $\mathrm{N}$ and $\mathrm{C}$ atoms on the surfaces are terminated by $\mathrm{H}$ atoms. In the slabs on the right-hand side, one $\mathrm{OH}-$ and one $\mathrm{H}$-termination are swapped. The swapped $\mathrm{OH}-$ and $\mathrm{H}$-terminations are shown as large balls. The relative energies of the slabs are also shown in $\mathrm{kJ} / \mathrm{mol}$. In both the $\mathrm{Si}_{3} \mathrm{~N}_{4}$ and $\mathrm{SiC}$ cases, the swap of the $\mathrm{H}$ - and $\mathrm{OH}$-termination gives higher energy. This result shows that the $\mathrm{Si}$ atom terminated by $\mathrm{OH}$ groups and $\mathrm{C}$ or $\mathrm{N}$ atoms terminated by an $\mathrm{H}$ atom are stable. 
(a)

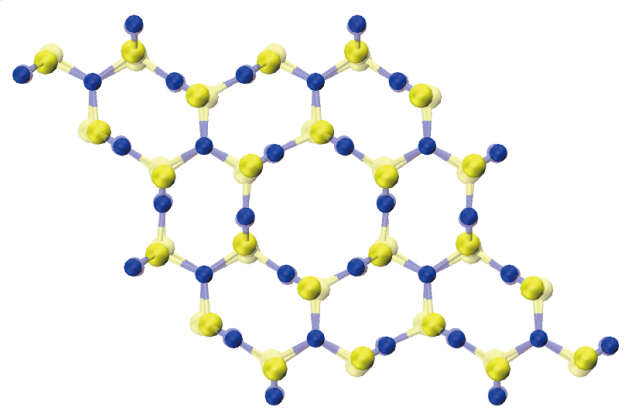

(b)

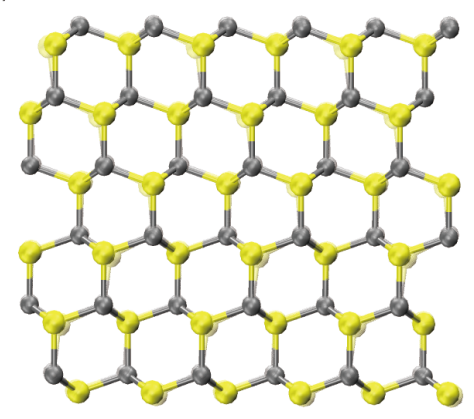

Figure S2. Optimized structure of non-terminated (a) $\beta-\mathrm{Si}_{3} \mathrm{~N}_{4}$ (0001) surface and (b) $6 \mathrm{H}-\mathrm{SiC}$ (1120) surface. Yellow, blue, and gray balls indicate $\mathrm{Si}, \mathrm{N}$, and $\mathrm{C}$ atoms, respectively. The optimized structure of the bulk $\beta-\mathrm{Si}_{3} \mathrm{~N}_{4}$ and $6 \mathrm{H}-\mathrm{SiC}$ are also shown by thin color. Significant reconstruction of the surface was not observed. 


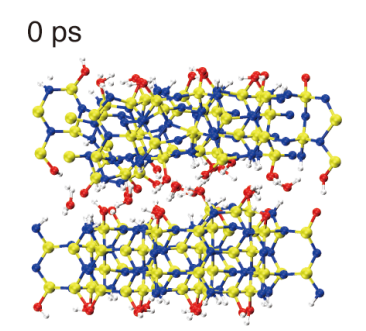

$10 \mathrm{ps}$
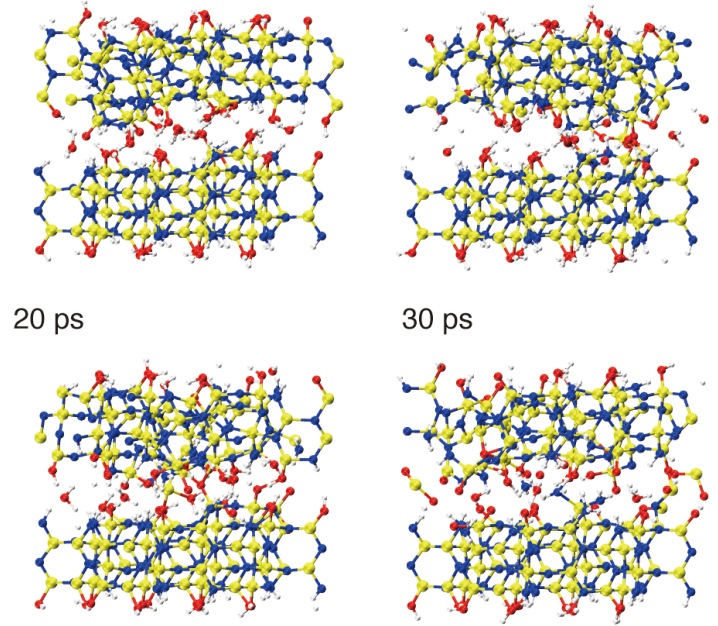

$30 \mathrm{ps}$

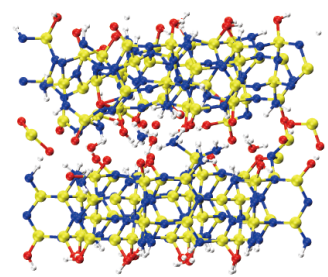

Figure S3. Snapshots of the sliding simulation of $\mathrm{Si}_{3} \mathrm{~N}_{4}$ for the $15 \mathrm{GPa}$ case.

(a)

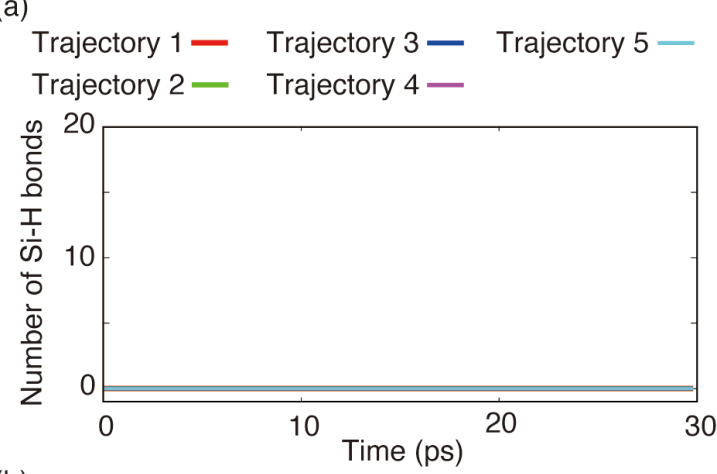

(b)

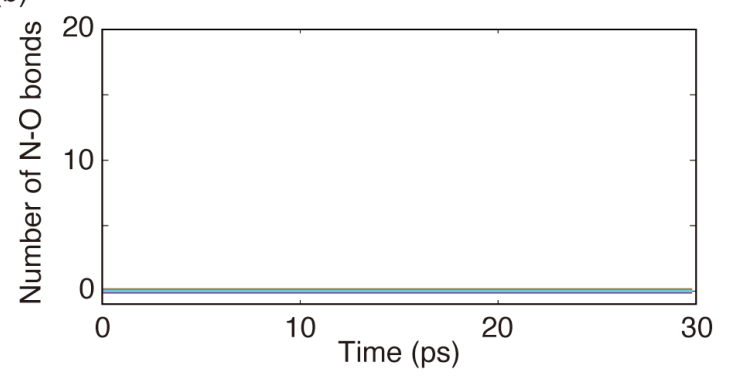

Figure S4. Temporal change in the (a) number of $\mathrm{Si}-\mathrm{H}$ bonds and (b) $\mathrm{N}-\mathrm{O}$ bonds in the sliding simulations of $\mathrm{Si}_{3} \mathrm{~N}_{4}$ for the $7 \mathrm{GPa}$ case. Five simulations were performed with different initial atomic coordinates and velocities. 
(a)

Trajectory $1-$ Trajectory $3-$ Trajectory $5-$ Trajectory 2 - Trajectory $4-$

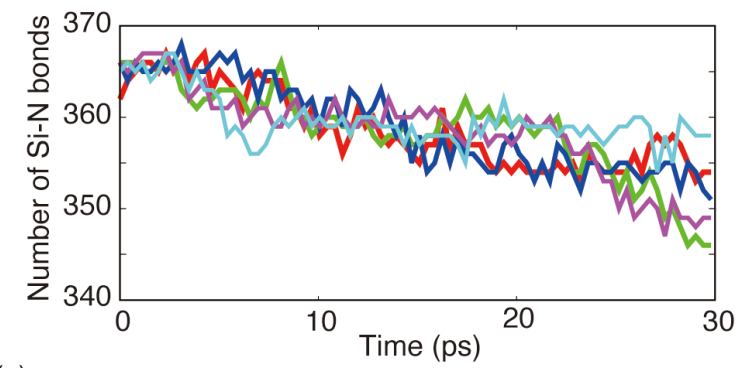

(c)

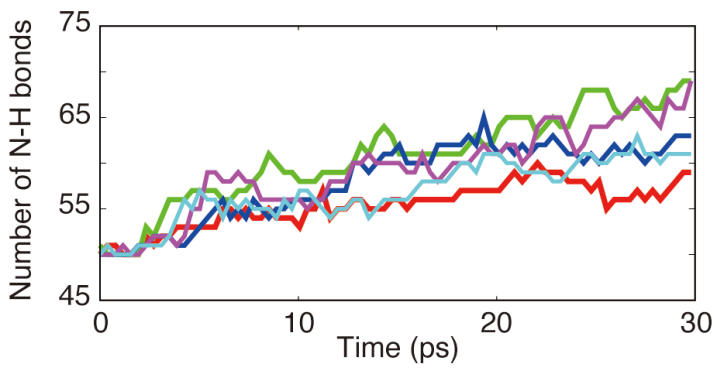

(e)

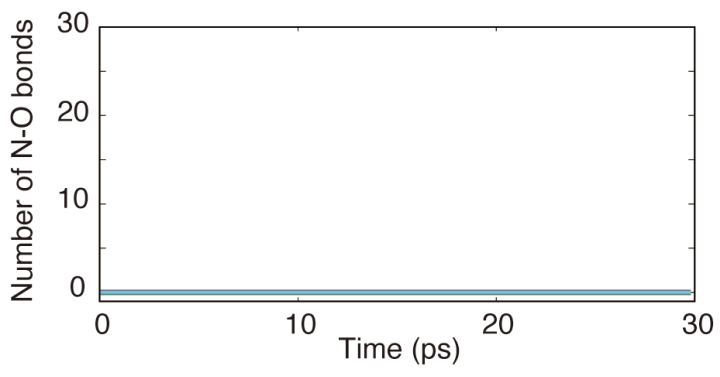

(b)

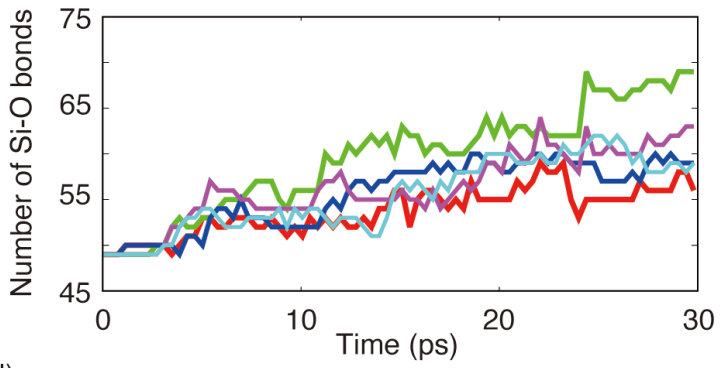

(d)

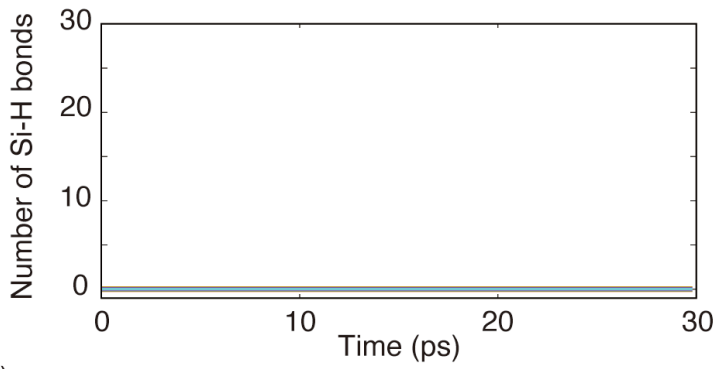

$(f)$

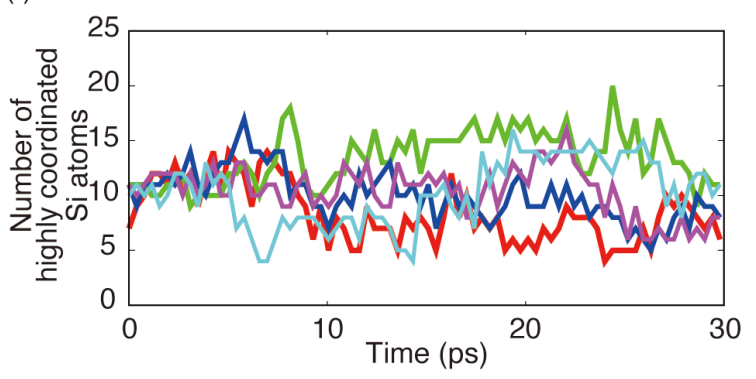

Figure S5. Temporal change in the number of (a) $\mathrm{Si}-\mathrm{N}$ bonds, (b) $\mathrm{Si}-\mathrm{O}$ bonds, (c) $\mathrm{N}-\mathrm{H}$ bonds, (d) $\mathrm{Si}-\mathrm{H}$ bonds, (e) $\mathrm{N}-\mathrm{O}$ bonds, and (f) highly coordinated $\mathrm{Si}$ atoms in the sliding simulations of $\mathrm{Si}_{3} \mathrm{~N}_{4}$ for the $15 \mathrm{GPa}$ case. Five simulations were performed with different initial atomic coordinates and velocities. 


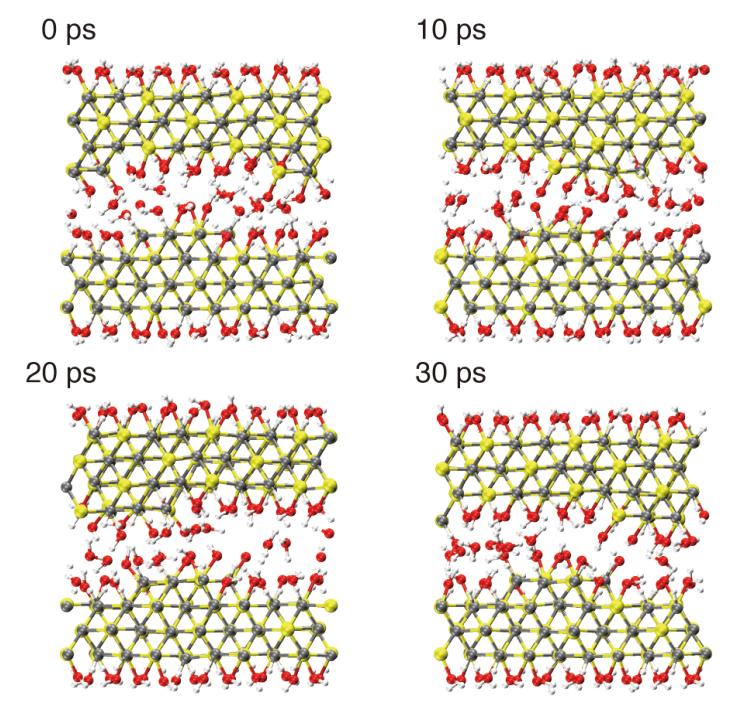

Figure S6. Snapshots of the sliding simulation of $\mathrm{SiC}$ for the $7 \mathrm{GPa}$ case.

(a)

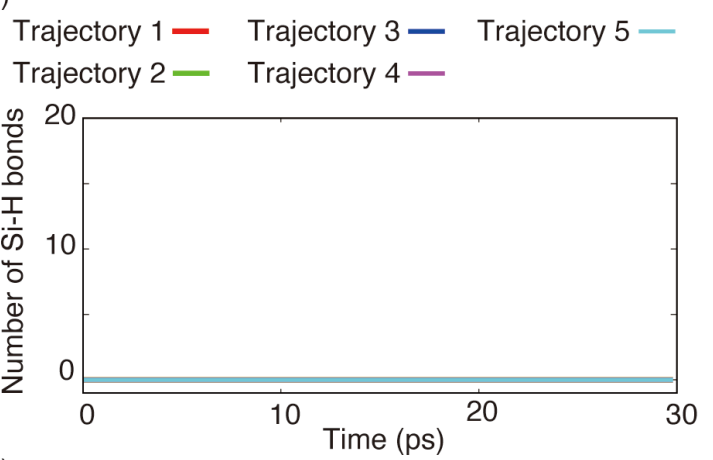

(b)

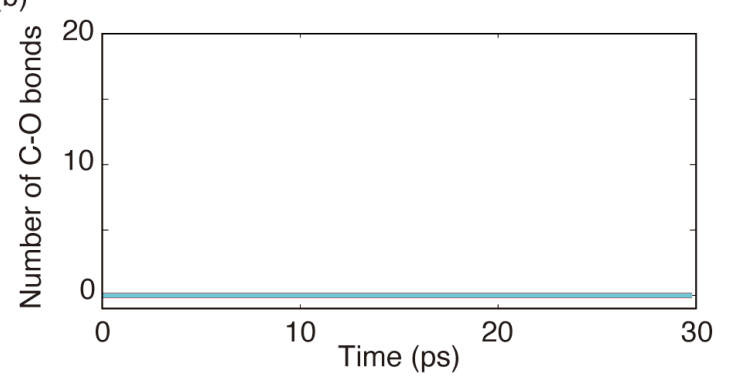

Figure S7. Temporal change in the (a) number of $\mathrm{Si}-\mathrm{H}$ bonds and (b) $\mathrm{C}-\mathrm{O}$ bonds in the sliding simulations of $\mathrm{SiC}$ for the $15 \mathrm{GPa}$ case. Five simulations were performed with different initial atomic coordinates and velocities. 
(a)

Trajectory 1 - Trajectory $3-$ Trajectory 5

Trajectory 2 - Trajectory 4 -

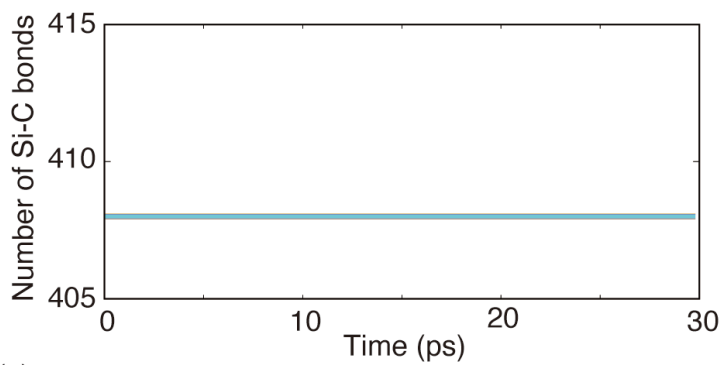

(c)

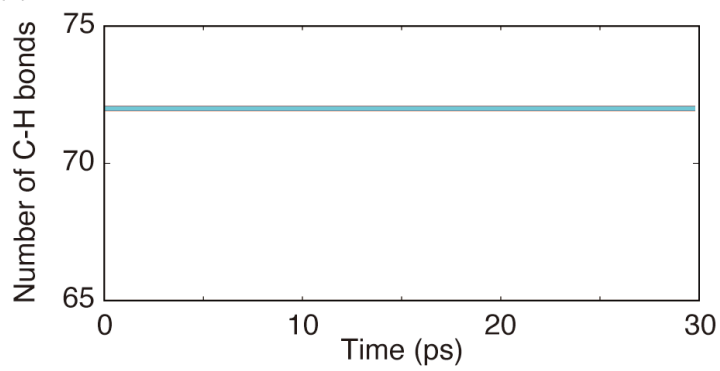

(e)

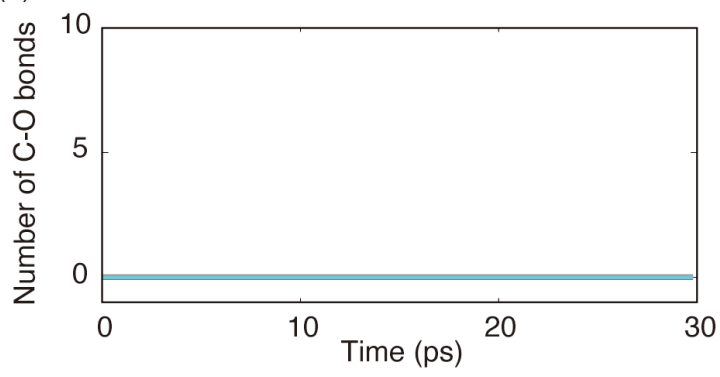

(b)

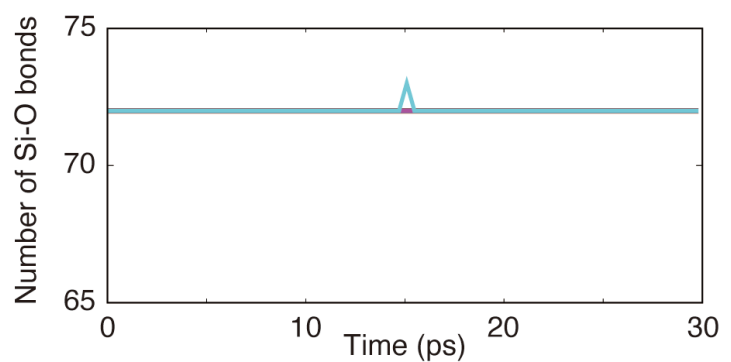

(d)

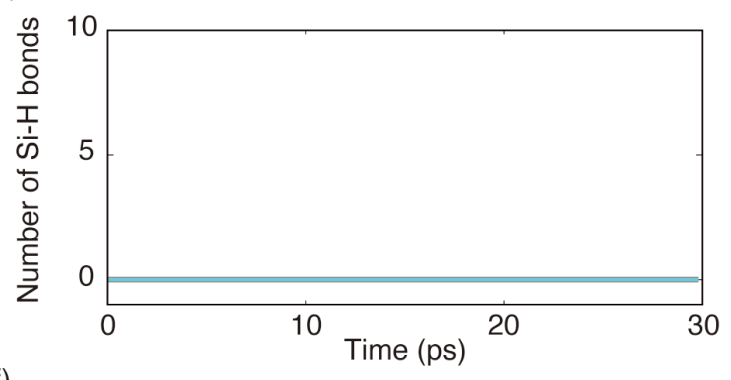

(f)

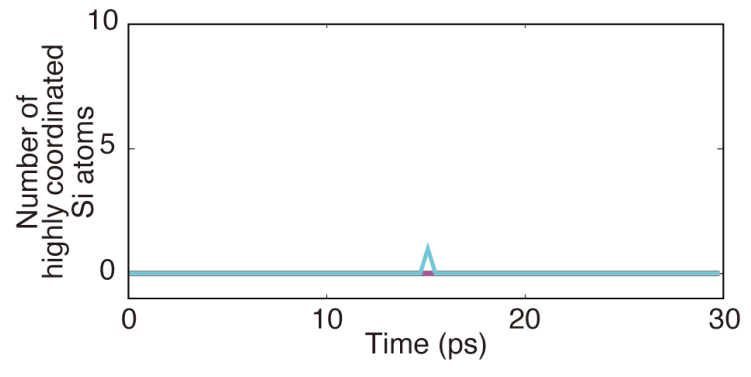

Figure S8. Temporal change in the (a) number of $\mathrm{Si}-\mathrm{C}$ bonds, (b) $\mathrm{Si}-\mathrm{O}$ bonds, (c) $\mathrm{C}-\mathrm{H}$ bonds, (d) $\mathrm{Si}-\mathrm{H}$ bonds, (e) $\mathrm{C}-\mathrm{O}$ bonds and (f) highly coordinated $\mathrm{Si}$ atoms in the sliding simulations of $\mathrm{SiC}$ for the $7 \mathrm{GPa}$ case. Five simulations were performed with different initial atomic coordinates and velocities. 


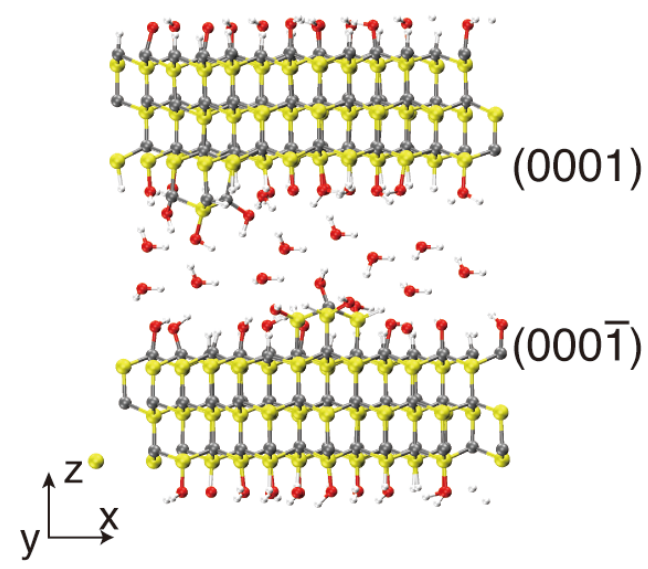

Figure S9. Sliding simulation model of $\mathrm{SiC}(0001)$ surface against $\mathrm{SiC}(000 \overline{1})$ surface in an aqueous environment. Yellow, gray, red, and white balls indicate $\mathrm{Si}, \mathrm{C}, \mathrm{O}$, and $\mathrm{H}$ atoms, respectively. Each surfaces are terminated by equal number of $\mathrm{OH}$ and $\mathrm{H}$ groups. The simulation cell had a hexagonal structure with the following parameters: $a=15.405 \AA, b=15.405 \AA, c=$ 25.000 $\AA, \alpha=90.0^{\circ}, \beta=90.0^{\circ}, \gamma=120.0^{\circ}$. The normal load corresponding to the contact pressure of $7 \mathrm{GPa}$ was applied. The other simulation conditions are the same as those documented in the manuscript. 
(a)

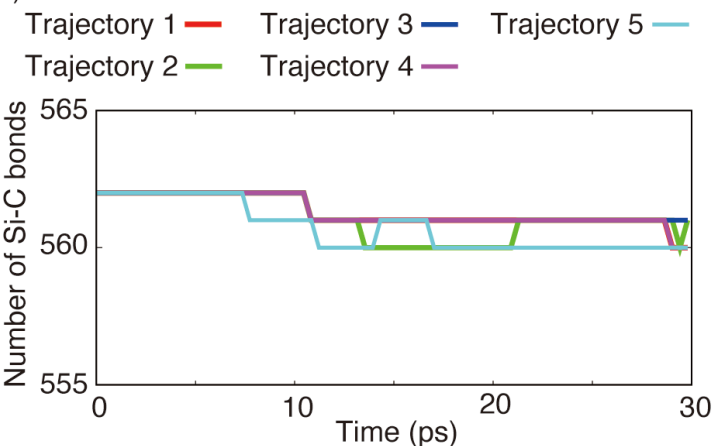

(c)

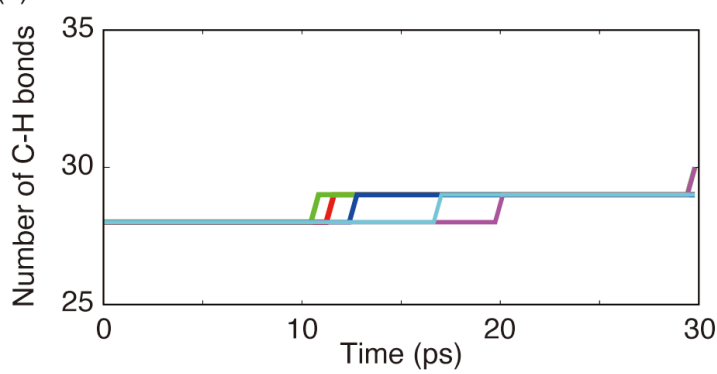

(e)

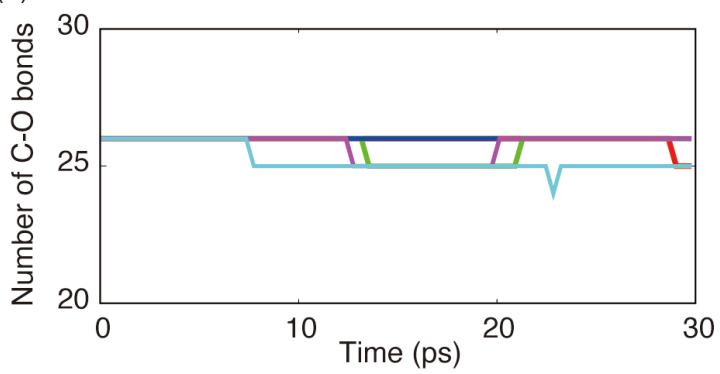

(b)

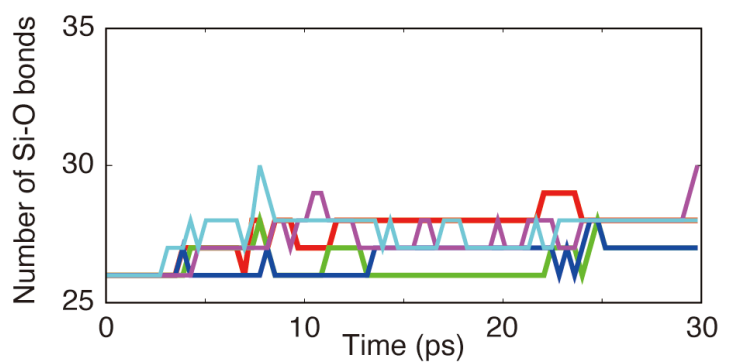

(d)

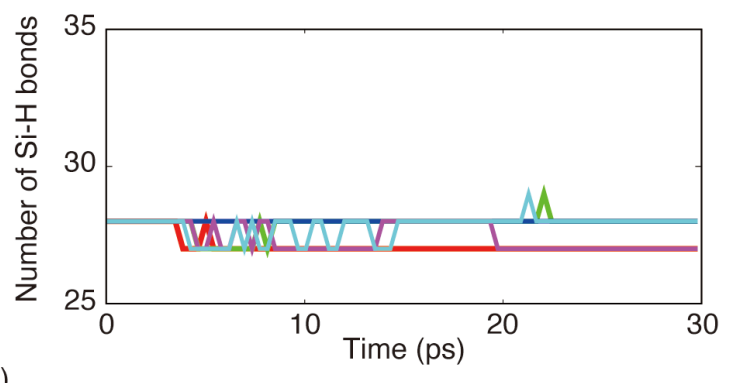

(f)

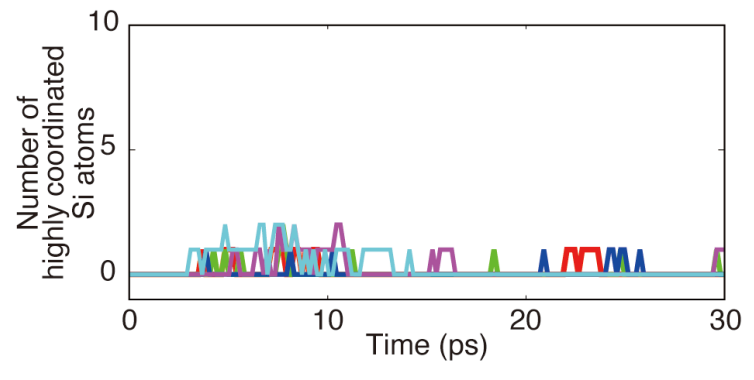

Figure S10. Temporal change in the (a) number of $\mathrm{Si}-\mathrm{C}$ bonds, (b) $\mathrm{Si}-\mathrm{O}$ bonds, (c) $\mathrm{C}-\mathrm{H}$ bonds, (d) $\mathrm{Si}-\mathrm{H}$ bonds, (e) $\mathrm{C}-\mathrm{O}$ bonds and (f) highly coordinated $\mathrm{Si}$ atoms in the sliding simulations of $\mathrm{SiC}(0001)$ surface against $\mathrm{SiC}(000 \overline{1})$ surface. Five simulations were performed with different initial atomic coordinates and velocities. 